\title{
Combined treatment with indapamide and perindopril but not perindopril alone reduced the risk for recurrent stroke
}

PROGRESS Collaborative Group. Randomised trial of a perindopril-based blood-pressure-lowering regimen among 6105 individuals with previous stroke or transient ischaemic attack. Lancet 2001 Sep 29;358:1033-41.

QUESTION: In patients with a history of stroke or transient ischaemic attack (TIA), is perindopril alone or combined with indapamide more effective than placebo for reducing fatal or non-fatal stroke?

Sources of funding:

Servier

Pharmaceuticals;

Health Research

Council of New

Zealand; National

Health and Medical

\section{Design}

Two* randomised (allocation concealed $\dagger$ ), blinded $\{\mathrm{pa}-$ tients, clinicians, data collectors, outcome assessors, data analysts, and manuscript writers $\}+, \dagger$ placebo controlled trials with a mean follow up of 3.9 years (Perindopril Protection against Recurrent Stroke Study [PROGRESS]).

For correspondence: not available.

Antihypertensive treatment $v$ placebo for stroke at a mean of 3.9 years $\$$

\begin{tabular}{lllll} 
Outcomes & $\begin{array}{l}\text { Perindopril }+ \\
\text { indapamide }\end{array}$ & $\begin{array}{l}\text { Double } \\
\text { placebo }\end{array}$ & RRR (95\% CI) & NNT (CI) \\
\hline Stroke & $8.5 \%$ & $14 \%$ & $43 \%(30$ to 54$)$ & 17 (13 to 27) \\
\hline Major vascular events & $13 \%$ & $21 \%$ & $40 \%(29$ to 49$)$ & $14(10$ to 20$)$ \\
\hline Outcomes & $\begin{array}{l}\text { Perindopril } \\
\text { alone }\end{array}$ & $\begin{array}{l}\text { Single } \\
\text { placebo }\end{array}$ & RRR (CI) & NNT \\
\hline Stroke & $12.3 \%$ & $12.9 \%$ & $5 \%(-19$ to 23$)$ & Not significant \\
\hline Major vascular events & $17.7 \%$ & $18.5 \%$ & $4 \%(-15$ to 20$)$ & Not significant \\
\hline
\end{tabular}

§Abbreviations defined in glossary; NNT and $\mathrm{Cl}$ calculated from data in article.

\section{COMMENTARY}

PROGRESS contains 2 distinct trials. The combination of perindopril and indapamide showed large and consistent benefits; perindopril alone did not. The results of the 2 trials should not be combined or even compared: the patients differed in age, blood pressure, and other features, and the results were heterogeneous.

The results of PROGRESS cannot tell us whether the benefits of combination treatment were from indapamide alone or from the combination of indapamide and perindopril. Support for a diuretic monotherapy effect comes from other studies, including the Post-stroke Antihypertensive Treatment Study, ${ }^{1}$ in which indapamide alone ( $v$ placebo) showed a $29 \%$ relative reduction $(\mathrm{p}=0.0013)$ in stroke recurrence. No single diuretic has been shown to be superior to any other diuretic. Stroke results for other ACE inhibitors are mixed and include the Heart Outcomes Prevention Evaluation (HOPE) trial, ${ }^{2}$ in which ramipril showed greater reductions than placebo, and the Captopril Prevention Project trial, ${ }^{3}$ in which captopril showed an increased risk for stroke over that with diuretics, or $\beta$-blockers, or both.

PROGRESS suggests that all stroke patients, regardless of hypertensive status, should be treated with a diuretic. Adding an ACE inhibitor can be considered on the basis of the large effect of combination treatment in PROGRESS or in the HOPE trial, but it has not been proved to give additional protection; direct comparisons of diuretics and diuretics plus ACE inhibitors are lacking. Furthermore, evidence continues to grow that patients with ischaemic stroke should be treated with some form of antithrombotic treatment and a coenzyme A reductase inhibitor (statin).

David Tirschwell, MD, MSc University of Washington School of Medicine Seattle, Washington, USA

1 PATS Collaborating Group. Post-stroke antihypertensive treatment study. A preliminary result. Chin Med J (Engl) 1995;108:710-7.

2 Yusuf S, Sleight P, Pogue J, et al. Effects of an angiotensin-converting-enzyme inhibitor, ramipril, on cardiovascular events in high-risk patients. N Engl J Med 2000;342:145-53.

3 Hansson L, Lindholm LH, Niskanen L, et al. Effect of angiotensin-converting-enzyme inhibition compared with conventional therapy on cardiovascular morbidity and mortality in hypertension: the Captopril Prevention Project (CAPPP) randomised trial. Lancet 1999;353:611-6.

\section{Setting}

172 centres from 10 countries.

\section{Patients}

6105 patients (mean age $64 \mathrm{y}, 70 \%$ men) who had a history of stroke or TIA in the previous 5 years, had no definite indication for or contraindication to an angiotensin-converting enzyme (ACE) inhibitor, and were clinically stable for $\geqslant 2$ weeks after their most recent vascular event. 6102 patients ( $>99 \%$ ) completed follow up for fatal events.

\section{Intervention}

Some patients were allocated to perindopril $4 \mathrm{mg}$ daily $(\mathrm{n}=1281)$ or to single placebo $(\mathrm{n}=1280)$. Other patients, for whom the responsible physician found no specific indication for or contraindication to a diuretic, were allocated to perindopril plus indapamide (indapamide dose 2.0 or $2.5 \mathrm{mg}$ daily) $(\mathrm{n}=1770)$ or to double placebo $(\mathrm{n}=1774)$.

\section{Main outcome measures}

Fatal or non-fatal stroke. Secondary outcomes included fatal or disabling stroke with the disability defined at the first scheduled follow up visit after the event and a composite vascular end point of non-fatal stroke, non-fatal myocardial infarction, or death from any vascular cause.

\section{Main results}

Analysis was by intention to treat. Patients who received perindopril and indapamide had greater reductions in blood pressure and in stroke, stroke subtypes, and vascular events than did patients who received double placebo $(\mathrm{p}<0.001)$ (table). Perindopril alone showed no more reduction in stroke or major vascular events than did single placebo (table). The relative effects of combination treatment did not differ in patients with and without a pre-existing diagnosis of hypertension.

\section{Conclusions}

In patients with a history of stroke or transient ischaemic attack, treatment with indapamide and perindopril was more effective than treatment with placebo for reducing fatal or non-fatal stroke. Treatment with perindopril alone was not effective.

*The authors disagree with our reporting of their study as 2 separate trials.

tSee glossary.

\$nformation provided by author. 